\title{
Noumenal Freedom and Kant's Modal Antinomy
}

\author{
Uygar Abaci \\ Pennsylvania State University \\ Email: uxa14@psu.edu
}

\begin{abstract}
Kant states in $\$ 76$ of the third Critique that the divine intuitive intellect would not represent modal distinctions. Kohl (2015) and Stang (2016) claim that this statement entails that noumena lack modal properties, which, in turn, conflicts with Kant's attribution of contingency to human noumenal wills. They both propose resolutions to this conflict based on conjectures regarding how God might non-modally represent what our discursive intellects represent as modally determined. I argue that (i) these proposals fail; (ii) the viable resolution consists in recognizing that we modalize human noumenal wills as a merely regulative-practical principle in our judgements of imputation.
\end{abstract}

Keywords: Kant; modality; freedom; noumenal will; antinomy

Kant makes a set of striking remarks in $\$ 76$ of the Critique of the Power of Judgement: ${ }^{1}$

It is absolutely necessary for the human understanding to distinguish between the possibility and the actuality of things. The reason for this lies in the subject and the nature of its cognitive faculties. For if two entirely heterogeneous elements were not required for the exercise of these faculties, understanding for concepts and sensible intuition for objects corresponding to them, then there would be no such distinction (between the possible and the actual). That is, if our understanding were intuitive, it would have no objects except what is actual. (5: 401-2)

For an understanding to which this distinction did not apply, all objects that I cognize would be (exist), and the possibility of some that did not exist, i.e., their contingency if they did exist, as well as the necessity that is to be distinguished from that, would not enter into the representation of such a being. (5: 403)

These remarks have inspired two strands of discussion in recent literature. One strand focuses on the epistemic thesis (ET) that while our discursive intellect must employ a distinction between the merely possible and the actual, an intuitive intellect would unrestricted re-use, distribution, and reproduction in any medium, provided the original work is properly cited. 
only represent the actual. Leech (2014) and Winegar (2017) have offered different accounts of why Kant holds this thesis, locating the answer in distinct aspects of the divine intuitive intellect. The other strand focuses on the metaphysical implications of this thesis. Kohl (2015) has argued that the ET entails the metaphysical thesis (MT) that noumena do not have any modal properties, as a specific instance of the general claim that the fact that the divine intuitive intellect would not represent things as instantiating any categories entails that noumena do not have any categorial properties, provided that such an omniscient intellect represents things as they really are in themselves. While Kohl's model of inference has later been criticized by Marshall (2018) as unwarranted, I have elsewhere made the case that the MT does not have to rely on this inference from the ET or any consideration regarding the nature of the divine intuitive intellect. I have argued that the MT can instead be derived directly from Kant's conception of modality, according to which modality is itself an exclusive feature of discursive cognition and modal notions do not even purport to represent properties of things in the first place but only the ways in which the conceptual representations of things are related to the distinct faculties of a discursive intellect (Abaci 2019). Regardless of how Kant's commitment to the MT should be justified, however, it poses problems for some of his other major philosophical commitments. Stang (2016) has pointed out one of these problems and argued that the MT constitutes an 'antinomy' with Kant's theory of human noumenal freedom, which, according to Stang, requires, via the principle of 'ought implies can', that our noumenal wills have the modal property of the possibility of doing or choosing otherwise. ${ }^{2}$

In this article, I wish to engage the latter strand of discussion and offer an alternative approach to the 'antinomy' in question. ${ }^{3}$ In section 1, I will examine Stang's and Kohl's proposed resolutions to the 'antinomy', both of which consist in creative conjectures as to how God's intellect might non-modally represent what our discursive intellects represent as modally determined, either through 'noumenal correlates' (Stang) or 'non-discursive senses' (Kohl) of our modal notions. I will argue that these proposals fail for different reasons but have in common that they misplace the resolution in a theocentric context. In section 2, I will first reconstruct the 'antinomy' as one between Kant's MT and his theory of human moral agency, instead of noumenal freedom, and then develop an anthropocentric alternative to these theocentric proposals. A viable resolution, I will argue, consists in recognizing that, while the MT follows from a theoretical reflection (either on the nature of divine intellect as Kohl has it or on the nature of modality as I have it), the proposition that human noumenal wills have modal properties or in particular 'ought implies can' is a merely regulative principle of practical reason that we are required to employ in our judgements of imputation of moral failures to human agents, and thus should not be understood as part of a positive description of human noumenal wills.

\section{The MT and noumenal freedom: a modal antinomy?}

Stang constructs the 'antinomy' between Kant's 'noumenal amodalism' and his theory of freedom through the following four propositions, all of which Kant appears to endorse: 
(P0) If there is a God, he has an intuitive intellect.

(P1) Some noumena have modal properties. [Consequence of the theory of freedom]

(P2) No intuitive intellect cognizes its object(s) as having modal properties. [CPJ §76]

(P3) Noumena have modal properties if and only if, if there is a God, God would cognize those properties. [Omniscience of God ...] (Stang 2016: 198)

Obviously, (P1) is inconsistent with what (PO), (P2) and (P3) jointly entail, i.e. the MT. Stang thus uses Kohl's generic model in deriving Kant's MT from his ET (P2), together with an epistemic feature of God (namely, his omniscience). ${ }^{4}$ Since Kant's commitment to MT is the central point of reference in this debate whether or not it really follows from the conjunction of (PO), (P2) and (P3), what matters the most here is (P1). In grounding (P1), Stang refers to Kant's principle of 'ought implies can' (OIC) and his resolution of the third antinomy (between freedom and determinism). The OIC states that if I ought to refrain from doing something, then I really can refrain from doing it or if I actually did not, I could have. And Kant's resolution of the third antinomy consists in the idea that even if, as a phenomenal being, all of my acts are causally determined and thus empirically necessary, as a noumenal being, '[I] can ... rightly say of every unlawful action [I] performed that [I] could have omitted it' (CPrR, 5: 98). From this Stang infers that Kant's theory of noumenal freedom presupposes that human noumenal wills have the modal property of possibility to choose or do otherwise (and thus, of the contingency of choice and action) (Stang 2016: 298, 299).

In the next section, I will dispute this particular construction of the problem, arguing both that Kant does not take the possibility to do otherwise to be an essential component of noumenal freedom and that Stang's claim that the OIC grounds such modal attribution to our noumenal wills requires significant qualification. Yet, setting aside Stang's presentation of the 'antinomy of Kant's modal metaphysics' for now, I will here look at the validity of his proposed solution to it.

Stang's strategy turns on the idea that there might be a non-discursive and non-modal way in which the divine intuitive intellect represents the modal contents of our representations, and his solution to the problem consists in positing 'noumenal (and supposedly non-modal) correlates' of what our discursive intellects represent as modal properties. Namely, Stang suggests that God's intuitive intellect would represent what we represent as possibility and actuality in or by representing the noumenal properties of 'dependence on God's essence' and 'dependence on God's will and essence'. This way, Kant's ET that modality does not enter into divine cognition and the omniscience requirement that nothing escapes divine cognition are both satisfied. This is quite an elegant thought indeed. Yet it runs into both textual and philosophical problems.

As the textual basis for his solution, Stang points to a passage from the Pölitz transcription of Kant's lectures on religion: 
We represent to ourselves that in cognizing his own essence (simplex intelligentia) God must also cognize everything possible, since he is the ground of all possibilities. Thus we derive the cognition of all possibilities from his nature and call it cognitio simplicis intelligentiae. - We think of scientia libera as God's cognition of the actual, insofar as he is simultaneously conscious of his free choice of things ... We think of scientia libera in God to the extent that in his cognition of everything possible, God is at the same time conscious in his free will of those possible things which he has made actual. (Th-Pölitz, 28: 1054)

Stang interprets Kant here as asserting that God cognizes everything possible by cognizing his own essence, since his essence is the (metaphysical) ground of all possibility, and that he cognizes everything actual by cognizing his own will, since his will is the (causal) ground of all actuality. The property of depending solely on God's essence and the property of depending on God's will as well as his essence would then be the respective noumenal correlates of possibility and actuality. What God represents as a distinction between two ways in which objects depend on him, we represent as a modal distinction between objects.

However, this passage does not really support Stang's 'noumenal correlates' reading. The context of this passage is Kant's critique of a distinction between three (not just two) kinds of divine knowledge. The explicit addressee of this critique is Baumgarten, but the same distinction is also found in Eberhard. ${ }^{5}$ According to this distinction, God's cognition is divided into (1) knowledge of simple intelligence, (2) free knowledge and (3) middle knowledge (scientia media). The first involves the cognition of everything unconditionally possible, the second everything actual (past, present and future) and the third counterfactuals (what could have existed in the world). While Stang (2016: 311) admits that Kant is critical of this distinction, he claims that Kant criticizes only the modal way in which it is cashed out, but does not deny that there is a distinction in divine cognition based on the different ways God cognizes himself (e.g. his essence vs. his will). But in fact Kant denies this distinction in the divine cognition altogether, and attributes the distinction, and not just our modal interpretation of it, to our own discursive representation of God's cognition. The crucial point here is that the fact that we interpret the distinction in modal terms is not separable from the fact that we make this distinction at all. Just before the passage Stang quotes, Kant says:

[Baumgarten's] division itself will hardly hold water if we try to think of it in relation to God. For the term scientia simplicis intelligentiae is understood by the author to mean the cognition of everything possible, while scientia libera means the knowledge of something actual. Yet in regard to God there is no distinction between the possible and the actual; for a complete cognition of the possible is simultaneously a cognition of the actual ... The distinction between scientia simplicis intelligentiae and scientia libera is to be found only in our human representation of God's cognition, and not in this cognition itself. (Th-Pölitz, 28: 1053)

That Kant takes the distinction to be inherently modal is hardly surprising given his emphasis, for instance in CPJ §76, that we make modal distinctions because of the 
different ways in which objects are related to our distinct and heterogenous cognitive faculties. ${ }^{6}$ Divine cognition is strictly amodal because the divine intellect is perfectly homogeneous and relates to its objects only in one way. God cognizes one unified whole of everything (presumably including himself and his relation to the rest of being) in a single, instantaneous and immediate act of representation. ${ }^{7}$

It is also worth noting here that Kant uses an extensional account of modality to undermine the distinction: a complete cognition of possibility is also that of actuality. So even if God did employ modal concepts, they would turn out to be coextensive in God's complete cognition of everything. ${ }^{8}$ However, such modal collapse due to omniscience cannot be what motivates Kant's considered view that divine cognition is amodal. Kant does not understand modality extensionally, that is, he does not hold that the difference between the possible and the actual is a matter of extension such that the extension of the former is greater than the latter. For he emphatically denies that modal notions are real predicates that can enter into the intension of the concept of any object and would make that concept's extension narrower. ${ }^{9}$ Thus, his reasoning here would be best understood as a tool designed for a reductio against Baumgarten, showing why Baumgarten's (extensional) account of modality does not support (and even undermines) his (extensional) distinction.

Stang acknowledges that the set of objects that depend on God's essence and the set of objects that depend on his will are one and the same, "there are no noumenal objects that only depend on God's essence without being created by his will'. ${ }^{10}$ Thus, the 'noumenal correlates' also turn out to be coextensive, picking out the same set of objects. However, if Kant holds that coextensiveness disqualifies Baumgarten's distinction, he would also hold it to disqualify the distinction Stang replaces it with. Perhaps to safeguard his account against this objection, he (Stang 2016: 313) switches from the modality of objects to the modality of properties: 'our concept of noumenal (real) possibility does not have a set of noumenal objects as its correlate, but a set of properties of noumena, the properties we represent as being (really) possibly instantiated'. Accordingly, the noumenal correlate of the possible instantiation of a property by a noumenon would be that property being grounded by God's essence, and that of the actual instantiation of a property by a noumenon would be that property being grounded by God's will.

What immediately strikes one here as troubling is that 'grounding' or 'dependence' and 'substance' (and 'property'), which constitute the contents of noumenal correlates of modality, are categories of relation, and thus discursive. Why should we assume that an intuitive intellect would employ a set of discursive notions in representing the non-discursive correlates of another set of discursive notions? Yet even more importantly, one would be tempted to ask whether 'grounding' does not really have a modal content, as it implies a necessary connection between the 'ground' and the 'grounded'. This threat of circularity gets more damning when Stang specifies the aspect of God's essence that grounds possibility as God's potential will or power. Accordingly, the noumenal correlate of the possible instantiation of a property is its dependence upon God's potential will or his power, as opposed to the noumenal correlate of the actual instantiation of a property, which is its dependence on God's will. The natural consequence of this formulation would be defining the noumenal correlate of the actuality of a volition/choice of my (noumenal) will as its being caused by God's will, and that of the possibility of my will's choosing otherwise as 
God's power to cause that alternative choice. Yet since this would threaten human noumenal freedom, Stang introduces one more twist and defines 'noumenal correlates of the actuality and possibility of determination in my will' as 'respectively, what my will chooses and my power to choose otherwise.. ${ }^{11}$ Thus, Stang's 'noumenal correlate' reading boils down to replacing the actuality of my will instantiating a property or an act with 'causing (itself) to instantiate that property or act' and its possibility to do so with "having the potential or power to cause (itself) to instantiate that property or act'. More specifically, Stang replaces the 'possibility of acting (or choosing) otherwise' with 'power/potential to act (or choose) otherwise'. Yet what exactly is power or potential if not the possibility of actualizing or causing an effect? Without a genuinely non-modal account of terms like 'power' or 'potentiality', Stang's noumenal correlates of actuality and possibility amount to 'having an actual cause' and 'having a possible cause. ${ }^{12}$ Stang's filler concept, 'noumenal correlate', which was supposed to do all the deflationary work, ends up recycling modality back into noumenal reality (and God's cognition of it) and thereby violating both Kant's MT and $\mathrm{ET}^{13}$

While Stang's is the most detailed attempt to resolve the modal 'antinomy' so far, Kohl has also offered a brief conjecture as to how the divine intellect would non-modally represent the modality of our free actions. Kohl's account turns on the idea of a non-discursive sense of modality:

[T]here is also a distinctively practical, non-discursive sense of modality. The moral law contains the idea of synthetic practical necessity: this idea is not peculiar to discursive thought since a divine being would cognize morally right actions 'as objectively necessary ... that is, as [unconditionally] good' (4: 412) (although it would not apprehend this necessity through an 'ought'; 5: 403). The representation of the practical contingency of free human action requires two components: the representation of rational necessity contained in the moral law, and the representation of the rational imperfection that afflicts our noumenal will (4: 413-414). Since a divine intellect would cognize both the moral law and our rational imperfection, it could intuit the practical contingency of free, law-governed human agency.

First, 'practical modality' for Kant is the modality of whether and how the moral law obligates or forbids certain actions. Thus, Kant lists practical senses of modal categories of possibility/impossibility, existence/non-existence and necessity/contingency in his table of the 'categories of freedom', respectively, as 'the permitted and the forbidden', 'duty and what is contrary to duty' and 'perfect and imperfect duty' ( $C P r R, 5: 66)$. However, not only is Kohl's claim that the latter are non-discursive notions disputable, since obligation or its derivatives such as permission, prohibition and duty would only apply to an imperfect will, but practical modality does not really capture what the 'antinomy' is about. For the 'antinomy' is about the modality of willing, or more precisely, the modality of how the will complies with the moral law, and although the context here is obviously practical, the relevant sense of modality is metaphysical (and theoretical). The contingency that is to be accounted for is the contingency of my noumenal willing relative to what the moral law obligates me to do and what my empirical inclinations impel me to do: my noumenal will is not causally 
(sufficiently) determined by either of them, and thus has the real or metaphysical possibility of going either way. Put in another way, the 'can' implied by 'ought' or the practical necessity of the moral law is not the permissibility of the action, though this is obviously implied by the moral law, but the metaphysical possibility of acting in the way it commands even in the face of contrary inclinations. So Kohl's appeal to the non-discursivity of practical modality, even if conceded, would not do much for the 'antinomy'.

Second, both the (practical) modality of the moral law itself and the (metaphysical) modality of willing in relation to it should rather be attached to our discursive representation of this normative relation. In particular, the 'objective necessity' mentioned in $G, 4: 412$, pertains to the way we represent the injunctions of the moral law. While Kant holds that the moral law is the law of all rational beings, whether they are perfectly or imperfectly rational, it does not follow that God, who would have a holy or perfectly rational will, cognizes the moral law as modally structured, i.e. as 'necessary' in either a practical or a metaphysical sense. As I implied above, the moral law would not 'obligate' or constrain a perfectly rational or good will like God's and thus would not register as practically necessary for the latter ( $G, 4: 414 ; C P r R, 5: 32-3)$. And such a will, enjoying freedom to the highest degree, would not be metaphysically necessitated to comply with the moral law either (Rel, 6: 51; Th-Pölitz, 28: 1068). Kant does attribute an 'inner necessity' to a holy will's willing the good (MM, 6: 222), as opposed to our contingency in doing so, in order to underscore the distinction between the ways in which the moral law applies to holy and human wills. But such modalization is still part of how we conceptualize this distinction. If the divine intellect does not represent mere possibilities (ET), it would not represent its own will's mere possibility of not willing the good, which, in turn, means that it would not represent its own act of willing as externally or internally necessary either. In other words, for the divine, what we represent as a 'law' (and thus as signifying a necessity) would just have to be a non-modal fact about itself. I will say more on this in section 2.

Third, since Kant construes the 'imperfection' of a will in modal terms, i.e. in terms of the (metaphysical) contingency of its compliance with the moral law ( $G, 4: 414 ; M M$, 6: 222), unless it is accompanied by a separate, genuinely non-modal account of what it means for a will to be perfect or imperfect, Kohl's suggestion that God would represent the contingency of our agency by representing the rational imperfection of our noumenal wills faces the threat of circularity just as Stang's does.

\section{Resolution of the modal antinomy}

Both Stang's and Kohl's proposed resolutions of the 'antinomy' involve creative conjectures regarding how God's intuitive intellect might non-modally represent what our discursive intellects represent modally. I suggest abandoning this theocentric strategy altogether. As I discussed above, such conjectures turn out to be circular. More importantly, though, they are not the appropriate tools for resolving antinomies. For God, if he is omniscient, would cognize the contents of our discursive intellects or how we represent things as well as how things really are in themselves. So God would represent modal properties, albeit indirectly, through representing our intellects, along with other properties, such as spatio-temporal properties, which 
belong merely to the way we represent things. ${ }^{14}$ Not only would God cognize any correlation relations there might be between the contents of these two modes of representation, but he would also be cognizant that his direct and thus non-modal representation of things is more adequate than our discursive and modal representation of them. Since antinomies arise only when there are two conflicting rival truth claims, no antinomy could even arise for such an intellect. The theocentric strategy, therefore, misplaces the 'antinomy' and consequently, its resolution.

Kant identifies 'antinomy' as 'a phenomenon of human reason' (A407/B433), resulting from conflicting needs of our cognitive faculties. Thus, the alternative strategy that I wish to pursue here approaches the problem from the opposite, i.e. anthropocentric, direction, and aims to answer the questions of whether, on Kant's theory of noumenal freedom, we really modalize our noumenal wills, and if so, in what sense we would be justified in modalizing what is in itself amodal. Such justification, if any, would offer a resolution to the 'antinomy' that is true to the spirit of Kant's own strategy in resolving antinomies: both the MT that noumena lack modal properties and the proposition that our noumenal wills have modal properties could be held simultaneously, once they are considered in relation to their distinct, appropriate standpoints, in accordance with our distinct cognitive needs.

\section{I Noumenal freedom and modality}

Let us first examine whether Kant's notion of noumenal freedom has a positive modal component such as the possibility of doing otherwise or contingency of action. While it can be argued that Kant's critical theory of freedom in general evolves from the first edition of the CPR (1781) through the MM (1797), he consistently construes noumenal or 'transcendental' freedom primarily negatively, as independence from all phenomenal causes (whether external, i.e. physical-biological, or internal, i.e. psychological) and thus from the determination of any temporally preceding ground. ${ }^{15}$ For any temporal event would be causally determined by, and necessarily relative to, other preceding temporal event(s). Thus, any act as a temporal event is unfree, for it has a sufficiently determining ground in the past, which is no longer within an agent's control. ${ }^{16}$ The act of volition, if it were to be free, would then have to be considered as an atemporal one. Thus, Kant complements the negative conception of noumenal freedom with a positive one, as an atemporal and thus uncaused or 'unconditioned causality' (CPrR, 5: 105), 'an absolute causal spontaneity' (A446/B474), 'beginning a state from itself (A533/B561). ${ }^{17}$ Kant's resolution of the third antinomy relies on this notion of absolute causal spontaneity that is uncaused by any phenomenal cause and yet causing phenomenal effects. Accordingly, each act can be considered both phenomenally, i.e. as determined by a cause preceding it in time and thus as unfree, and noumenally, i.e. as determined by an atemporal and spontaneous cause and thus as free. Kant also claims that the morally relevant notion of freedom, i.e. practical freedom, understood negatively as the capacity to act independent of sensuous impulses or desires, and positively as the capacity to act from the representation of moral or rational maxims or principles, is grounded on noumenal freedom (A533-4/B561-2). For such a rationally (as opposed to sensuously) motivated act presupposes independence from phenomenal causation as well as a causality that is not phenomenal (A534-5/B562-3). 
These characterizations of noumenal freedom do not have to be construed as modally loaded. For, first of all, 'independence' can be read simply as the denial of the presence of a dependence relation, and, as I will discuss later on, Kant holds that 'absolute spontaneity' is in fact completely mysterious to us. The key here is to recognize that the contrast between noumenal freedom and nature is not between contingency and necessity, but between the absence and the presence of modal constraints. Not being necessitated by anything and being absolutely spontaneous, respectively, entail contingency or alternate possibilities only in a modally structured domain. But Kant's MT portrays a modal vacuum where modal determinations are absent, and thus, where the lack of necessity would not amount to contingency or alternate possibilities.

Kant makes this especially clear in the case of divine freedom:

Freedom does not consist in the contingency of action ... i.e. not indeterminism ([the thesis] that God must be equally capable of doing good or evil, if his action is to be called free) but in absolute spontaneity. The latter is at risk only with predeterminism, where the determining ground of an action lies in antecedent time. (Rel, 6: 51)

One might raise the objection that God cannot decide otherwise than he does, and so he does not act freely but from the necessity of his nature ... but in God it is not due the necessity of his nature that he can decide only as he does, but rather it is true freedom in God that he decides only what is in conformity with his highest understanding. (Th-Pölitz, 28: 1068)

Thus, freedom requires the absence of any preceding modal constraints on volition. God, through his holy will, would always do good, and yet this lack of the alternate possibility of not doing good should not mean that God is determined to will or do good by necessity, and thus is not free. ${ }^{18}$ Noumenal amodalism, then, leads to neither necessitarianism, nor indeterminism, and seems not only compatible with but also strongly suggested by Kant's understanding of divine noumenal freedom. ${ }^{19}$

But what exactly would it mean to will or act with absolute spontaneity, that is, in a modal vacuum, where there are no antecedent necessities or possibilities, but only actuality? One could think of this in terms of Kant's actualism operative in his 'only possible proof', according to which possibilities must always be grounded in actualities, and God's actuality is the ultimate ground of all possibilities. ${ }^{20}$ The absolutely spontaneous action is neither determined nor bound by any antecedent modal constraints, but is what opens up the modal space in the first place. Accordingly, the alternate possibilities of an agent's doing A or not doing A would derive from their (absolutely spontaneous) action A itself rather than being options that precede and constrain the actual A. The action A is then not an actualization of one of two alternate possibilities, but what grounds those possibilities. Yet Kant insists that the precise mechanism of such absolute spontaneity is still incomprehensible to us in its own terms (Rel, 6:21, 44). Hence, he holds that a metaphysical proof of noumenal freedom would not be available to our discursive finite minds, and that the only ratio cognoscendi of freedom is morality (CPrR, 5: 5; CPJ, 5: 403). This also points to the 
appropriate ground of justification for our modal attributions to noumena, if any, despite our epistemic restrictions.

Now, even if Kant's conception of noumenal freedom per se does not have to be regarded as carrying positive modal content, let us recall that Stang points to Kant's principle of 'ought implies can' (OIC) as the ground of his claim that human noumenal freedom requires the attribution of possibility to do otherwise and contingency to our noumenal wills. I suggest that the OIC does not warrant a modalized notion of human noumenal freedom either.

First, Kant's formulations of the OIC concern the possibility of acting in accordance with the moral law, despite contrary empirical stimuli, in cases where the agent actually fails to do so (A555/B583; CPrR, 5: 98, 142; Rel, 6: 41, 45, 62). Thus, even if the OIC entails the possibility of doing otherwise, such modal attribution applies only to a subset of our free actions, i.e. the heteronomous ones. We can still be noumenally free in cases where we have no empirical inclination contrary to the duty. So Kant does not understand the possibility to will/do otherwise to be a necessary condition of our noumenal freedom. ${ }^{21}$ Instead of the other way around, Kant understands noumenal freedom as the necessary condition of having such a capacity for a finite will: only if an agent's will can determine itself (in accordance with a pure practical law) without being determined by empirical inclinations, can she have the capacity to do otherwise than what those inclinations would causally determine her to do.

Since Kant's discussions of the OIC focus on the possibility of moral success in cases that involve actual moral failure, they obviously presuppose that humans have the possibility of moral failure. In fact, Kant takes this latter possibility to be crucial to the particular kind of will human will is, and to the application of the moral law to human will as a constraint, an 'ought' ( $G, 4: 414)$ or 'imperative' (MM, 6: 222). ${ }^{22}$ As opposed to an animal will (arbitrium brutum), which is determined only by sensible impulses, i.e. pathologically, human will, as noumenally free (arbitrium liberum), is not determined pathologically, but can be determined rationally, i.e. by pure practical reason or its law (A802; CPrR, 5: 28-9; Met-L1, 28: 256-7). On the other hand, as opposed to a holy will, which is perfectly rational and has no pathological component, human will, as finite and only imperfectly rational, can be pathologically 'affected' (CPrR, 5: 32), even if not so determined. It is worth noting that while pathological determination signifies the causal force of a law of nature dictating that the effect follow necessarily, rational determination signifies the normative force of a practical law which obligates compliance without causally necessitating it. ${ }^{23}$ Thus, human will is open to the influence of two kinds of incentives, sensible and rational, and yet not causally determined by either to the exclusion of the other. In other words, neither kind of incentive is, by itself, a motive for human will ineluctably causing it to act, but human will can freely 'incorporate' one or the other into its maxims to make them into motives. ${ }^{24}$ This is why Kant defines at least one function of human will as a power of choice (Willkür), 'a faculty to do or refrain from doing as one pleases' (MM, 6: 213).

While Willkür is the power of choice that can choose to be motivated by sensible impulses or the moral law, Wille is the 'practical reason itself (MM, 6: 213), the capacity to set rational principles that can motivate the choice. As Beck (1987: 37) famously puts it, Wille is the legislative and Willkür is the executive faculty. Kant emphasizes 
that only the executive choice of Willkür is free, but Wille 'cannot even be called either free or unfree, since it is not directed to actions but immediately giving laws for the maxims of actions' (MM, 6: 226). There is no (metaphysical) necessity that the executive capacity, which is immediately related to action, harmonize with the legislative capacity and adopt the moral form the latter sets for the action. For, as spontaneous and yet pathologically affectable, the former might adopt an immoral maxim. The harmony between what the human agent wills and what she ought to (and thus can) will is always contingent.

However, despite the important role he assigns to the possibility of moral failure in his conception of human will, Kant's position ultimately articulated in $M M$ is to emphatically reject defining human freedom in terms of this negative possibility.

[A]lthough experience shows that the human being as a sensible being is able to choose in opposition to as well as in conformity with the law, his freedom as an intelligible being cannot be defined by this ... We can also see that freedom can never be located in a rational subject's being able to choose in opposition to his (lawgiving) reason. ... Only freedom in relation to the internal lawgiving of reason is really an ability; the possibility of deviating from it is an inability. How can the former be defined by the latter? (MM, 6: 226-7)

Kant does not deny here that the heteronomous choices of agents are free. What he denies is that the possibility of choosing against the moral law, which expresses the sensible aspect of human agency, is definitional of freedom, which expresses the noumenal aspect of human agency. For Kant clearly sees this possibility as the failure to carry out proper use of the capacity that is freedom, though such misuse is still a use of that capacity and thus is free.25

For these reasons, Stang's claim that Kant's commitment to the OIC leads him to construe noumenal freedom modally does not seem warranted. However, one might rightfully insist that Stang's (P1), 'some noumena have modal properties', can still hold up, since even if Kant's conception of noumenal freedom does not do so, his conception of human moral agency commits him to the attribution of possibility to do otherwise to human noumenal will.

\subsection{Possibility to do otherwise}

The question then is how to understand this modalization of human noumenal will. Let us first consider taking it as part of the theoretical description of human noumenal will. Accordingly, every human action, as a phenomenon, is causally determined by the past and thus the agent could not have refrained or done otherwise. However, the same action can also be considered as resulting from a noumenal character or will, which is not determined by temporal conditions but absolutely spontaneous. Such a will has the positive possibility of determining itself otherwise and of refraining from the action in question. Now, not only does this reading conflict with Kant's noumenal amodalism, but it also leads to a string of other difficulties threatening the coherence of his theory of human moral agency. I will mention only a few. 
The possibility of my noumenal will's self-determining otherwise entails the possibility of my temporal action, grounded by that atemporal volition, being otherwise. However, given that my temporal action is also causally determined by the chain of past events, the possibility of the former's being otherwise entails the possibility of the latter's being otherwise as well. Thus, my alternative noumenal volition would bring about an alternative causal history of the world. On the assumption that one is responsible for what they could have omitted, some scholars point out that this account allows one to be held responsible for the events that transpired before their birth and even for laws of nature. ${ }^{26}$ Aside from their blatant implausibility, such consequences undermine Kant's motivation to posit noumenal freedom as an atemporal ground for our actions: the past is not in one's control and nothing determined by the past can be imputed to an agent.

The idea of an atemporal character is difficult enough to comprehend in itself. First, a character, if it can be held morally responsible for its failures, must have some sort of psychological continuity, which, in turn, is representable by us only in temporal terms. Yet the freedom of a noumenal volition lies precisely in its temporalcausal discontinuity with the past: each such volition is the beginning of a new causal series from itself as if it is a singular, isolated instance. Second, paradoxically, since we can only represent change as located in a causal-temporal order, no change or 'new' state can be attributed to the noumenal character either. Kant states that, in the noumenal character, 'nothing happens, thus no alteration requiring a dynamical time-determination is demanded' (A541/B569); 'no before or after applies' (A553/B581); '[i]t ... never enters into a new state in which it previously was not' (A555/B584). But if a new or alternate state is not attributable to the noumenal character, how is the possibility of having willed otherwise attributable to it? A character that would have willed otherwise would be a different character! $!^{27}$ Third, the lack of continuity and change in character would make it impossible for us to better ourselves, even though the possibility of such self-betterment is required both by Kant's doctrines of virtue and radical evil and by the OIC itself. In other words, the modalization of an atemporal character is a profoundly problematic idea in itself.

There is at least one passage where Kant hints at an alternative metaphysical interpretation of the possibility to do otherwise, which would avoid violating noumenal amodalism and some of these problems. Emphasizing that the noumenal will or reason does not change, Kant writes:

[I]n regard to a new state, reason is determining but not determinable. Therefore one cannot ask: Why has reason not determined itself otherwise? But only: Why has it not determined appearances otherwise through its causality? But no answer to this is possible. For another intelligible character would have given another empirical one; and if we say that regardless of the entire course of life he has led up to that point, the agent could still have refrained from the lie, then this signifies only that it stands immediately under the power of reason, and in its causality reason is not subject to any conditions of appearances or of the temporal series ... (A556/B584, my emphasis)

Apart from noting that a different choice or self-determination would indicate a difference in character, a problem on which I have already commented, not only does 
Kant explicitly acknowledge here the inapplicability of the possibility of self-determining otherwise to the noumenal will, but he also offers a non-modal interpretation of the 'possibility to have done otherwise': the action, regardless of its causal determination by the past, is an immediate effect, and thus in control, of the noumenal will, which is not caused by anything else. Accordingly, the moral agent's possibility of doing otherwise is less about her having a 'leeway' to do or refrain from doing a certain action but more about her being the proper 'source' of that action. This suggests a negative understanding of the OIC, according to which 'can' signifies a mere lack of necessary determination of the will by the past. ${ }^{28}$ And finally, this account is compatible with a non-modal conception of noumenal freedom as the mere absence of being determined by any temporally antecedent grounds and absolute spontaneity.

\subsection{Modalization of will as a regulative principle of practical reason}

It would have been convenient to stop here. For it appears that as far as the metaphysics of the noumenal will goes, Kant retreats from the positive possibility of doing otherwise to amodalism. However, first, this would run into one of the problems confronting Stang's account. Even if Kant does not include positive modality in his notion of noumenal will, we have no other way of understanding the latter than as a 'capacity' or 'power' (of determination), which, in turn, invokes modal representation. Second, Kant often goes beyond this rather modest metaphysical position and repeatedly associates the possibility of doing otherwise with human moral responsibility and agency.

Perhaps this should all be expected, given Kant's ET that it is a necessary feature of our discursive intellects to represent things modally. Kant might then hold that, while theoretical reflection on the divine intuitive intellect or on the nature of modality leads us to noumenal amodalism, when we nevertheless represent our relationship to the moral law, we are compelled to modalize our noumenal wills. For, as I discussed earlier, human will can motivate itself either rationally or sensibly and has a split structure between its two distinct capacities, legislative and executive, the harmony of which is never guaranteed. While absolute spontaneity is inscrutable to us as such, we can represent our own spontaneous volition only as relative to two distinct sources, the moral law and our happiness, and thus as consisting in a contingent choice between two determinate possibilities, i.e. prioritizing one over the other. Thus we construe the moral law as an 'ought', a constraint on us, demanding priority over another possibility, and our moral responsibility as upholding this demand. If there is any hope of resolution here, it should lie in the kind of validity that is to be ascribed to such modal representation of noumenal volition in the face of the fact that from a theoretical perspective this representation is inadequate.

At this point, it is useful to go back to the original context of Kant's remarks in CPJ §76. Kant's broader claim is that certain ways in which we represent things are due to the particular, i.e. discursive, constitution of our intellect, even though they would not be represented so by another, i.e. intuitive, kind of intellect. For instance, following his ET that a discursive intellect modalizes its objects due to its split cognitive structure, while an intuitive intellect, which has no sensible or receptive component, would have only actual objects, Kant argues that even though we can only 
represent the moral law in terms of obligations or imperatives, for a purely rational being with an intuitive intellect, 'there would be no distinction between what should be done and what is done' and what the moral law requires would be neither necessary nor contingent, but only actuality, 'a be (happening)' (5: 403). He further argues that like the distinctions between the possible and the actual, and between what is and what ought to be, the distinction between 'a natural mechanism and technique of nature' or between efficient and teleological causation is also due to our discursivity, and an intuitive intellect would find no such distinction in nature (5: 404). ${ }^{29}$

Now, the upshot of Kant's insistence that we make these distinctions only due to the discursivity of our intellect and that they would not be made by a divine intellect is that these distinctions do not in fact pertain to the objective constitution of things. Thus, any proposition that involves these distinctions would only be 'subjectively valid' relative to our discursive intellect. Moreover, the resolution Kant offers for the antinomy between the thesis that all generation of material things is possible in accordance with mechanical laws and the antithesis that the generation of natural organisms is not possible in accordance with merely mechanical laws but requires final causation, is to recognize that since the distinction between mechanism and teleology is only subjectively valid for our understanding, these propositions should not be taken as principles constitutive of objects themselves but only as maxims regulative of the way we judge them (CPJ, 5: 387-9). Kant holds that the appearance of a contradiction between these propositions vanishes when they are viewed not as descriptive of objects and having objective validity, but as having only prescriptive or heuristic value in our subjectively constrained judgements of objects. In other words, the resolution lies in shifting the modal emphasis in these propositions from natural organisms themselves to our judging or mode of inquiry into them. To say, for instance, that natural organisms cannot be judged possible except as products of final causes is not to say that they are, as a matter of fact, not possible in accordance with mechanical laws and thus does not negate the maxim that all material nature must be judged as products of mechanical laws and efficient causes. The lesson here is that we are licensed to and sometimes even compelled to adopt heuristic tools in judging things without having to make metaphysical commitments about the objective constitution of those things.

If Kant offers this strategy as a resolution to an antinomy that stems from a distinction that we are constrained to make due to the discursive nature of our intellect, he would also allow a similar resolution to an antinomy that stems from the modal distinctions we are similarly constrained to make in our representation of things. Thus, rather than taking Kant's references to the possibility of willing/doing otherwise as theoretical statements purporting to describe the metaphysical mechanics of human noumenal volition, one could understand the modalization of the human free will as a regulative principle that we are both entitled and required to employ in our judgements of moral responsibility. And not only is this a plausible interpretative strategy, but it is also strongly corroborated by the fact that Kant's narrative in his discussions of the OIC is consistently from the standpoint of a moral judge (either as a third or first person) and constructed to uphold the rationality of judgements of imputation or blame regarding moral failures. ${ }^{30}$

For example, regarding the man who is forced by his prince to give false testimony against an honourable man on pain of execution but would admit that it would be 
possible for him to resist this threat, Kant says that 'he judges, therefore, that he can do something because he is aware that he ought to do it' (CPrR, 5: 30; emphasis added). More generally, he argues that, 'considered [as a noumenon], every rational being can ... rightly say of every unlawful action he performed that he could have omitted it even though as appearance it is sufficiently determined in the past and, so far, is inevitably necessary' ( $C P r R, 5: 98$; emphasis added). Again, in positing radical evil, Kant resorts to the same principle of imputation: 'Every evil action ... whatever the natural causes influencing him ... can and must always be judged as an original exercise of his power of choice. He should have refrained from it' (Rel, 6: 41; emphasis added). He repeatedly states that we 'must judge' (MM, 6: 380), 'must suppose' (CPrR, 5: 142), 'rightly conclude' (Rel, 6: 49) that we have the possibility of doing (as well as failing to do) as the moral law commands, if we are to have a coherent conception of ourselves as agents responsible for our actions.

In fact, in his much discussed example of the 'malicious liar', Kant explicitly calls this maxim of imputation 'the regulative principle of reason' (A554/B582), which one should adopt when one wants to take a voluntary immoral action and 'investigate its moving causes' in order to see how that action and its consequences could be imputed to the agent. While the process of investigation could reveal natural sources influencing the agent's empirical character, such as 'bad upbringing' or 'wickedness of a natural temper insensitive to shame', the regulative principle of imputation would urge the moral judge of the action to set aside all of that agent's 'life that he has led previously', and trace blame back to an unconditioned condition or an uncaused cause, that is, regard the action 'as entirely unconditioned in regard to the previous state, as though with that act the agent has started a series of consequences entirely from himself' (A554-5/B582-3; emphasis added). The moral judge thus bases their 'judgment of imputation' merely on the 'law of reason, which regards reason as a cause that, regardless of all the empirical conditions just named, could have and ought to have determined the conduct of the person to be other than it is' (A555/B583; emphasis added). Thus, while from the standpoint of empirical psychology, one should employ an empirical-temporal method of investigation into the determining causes that make the action inevitable in the natural order of events, from the standpoint of moral blame or imputation, one should employ the principle of 'ought implies can' and presuppose that the noumenal will of the agent could have chosen otherwise, regardless of whatever determining empirical causes the first method might find out. The adoption of such a heuristic in judging human actions is not only what it takes to treat humans as moral agents fully accountable for their failures, but it also has the practical interest of providing a self-critical and reflective perspective for the moral betterment of ourselves, growing more virtuous, more resistant to the temptations of our sensuous inclinations, and more resolved to follow the moral law in the face of empirical conditions unfavourable to our moral success. It is the starting point of building such resolve to judge oneself 'capable of resisting and conquering by reason' the impulses of nature: 'he must judge that he can do what the law tells him unconditionally that he ought to do' (MM, 6: 380). ${ }^{31}$

of course, as I noted earlier, how the noumenal will or its absolute spontaneity really works is bound to remain a mystery to us. And theoretical reflection on the divine intellect or modality would have us hold that noumena lack modal properties (MT). However, when we are urged, by practical reason, to represent human 
noumenal volition in the normative-evaluative context of judgements of moral blame and imputation, we represent it in modal terms, i.e. in the only way possible for our discursive intellect. The crucial point here is that, once viewed as a regulative principle, the attribution of possibility to do otherwise to an agent's noumenal will does not purport to have objective validity and thus does not challenge the objective validity of the MT. That is to say, (1) 'noumena lack modal properties' and (2) 'noumenal will has modal properties' are not two propositions on a par with each other: (1) is about how things are in themselves, and (2) is about how we ought to represent human noumenal selves in the practical context, and not an article of theoretical cognition regarding the mind-independent texture of reality itself. In fact, when situated in its regulative bracket, (2) amounts to $\left(2^{*}\right)$ 'we ought to represent human noumenal wills as having a modal property, once we recognize ourselves as moral agents responsible for our moral failures' ${ }^{32}$ While (1) follows from a theoretical reflection, (2) follows from a need of practical reason, that is, a subjectively necessary presupposition of practical reason in normative evaluation of human actions. There is then no contradiction as such. (1) is objectively valid from a theoretical perspective, and (2) is subjectively valid from a practical and regulative perspective, and carries no metaphysical import. ${ }^{33}$ If there is any resolution of the conflict between Kant's MT and the requirements of representation prescribed by his theory of moral agency, it lies in this difference. ${ }^{34}$

\section{Conclusion}

If my account above is correct, Kant holds the following consistent set of propositions. Noumena lack modal properties (MT). Noumenal freedom as absolute spontaneity is itself amodal. Noumenal volition is not bound by any modal constraints and takes place in a modal vacuum. The metaphysics of how this works is theoretically inscrutable to us in its own terms. Yet we nevertheless represent human noumenal will in modal terms, i.e. as having the possibility of willing or doing otherwise, due to the discursivity of our understanding. While this modal representation of a certain subset of noumena appears to constitute an antinomy with the MT, this appearance is removed once we recognize that the former is only a subjectively valid regulative principle of practical reason that we are required to adopt in our judgements of imputation of actions to human agents and not descriptive of our noumenal wills. ${ }^{35}$

\section{Notes}

1 I provide author-date citations for all authors except Kant. Kant's works are cited according to Kant (1900-), except for the Critique of Pure Reason, which is cited according to the standard A/B pagination. I follow the translations in Kant (1992-) when possible. I adopt the following abbreviations: $C P R=$ Critique of Pure Reason, $\mathrm{CPrR}=$ Critique of Practical Reason, $\mathrm{CPJ}=$ Critique of the Power of Judgement, $G=$ Groundwork of the Metaphysics of Morals, JL = Jäsche Logic, Log-D = Dohna-Wundlacken Logic, Log-W = Vienna Logic, $M M=$ Metaphysics of Morals, Met-L1 = Metaphysik Pölitz, Met-K3 = Metaphysik Arnoldt, OPA $=$ The Only Possible Argument in Support of a Demonstration of the Existence of God, Refl = Kants handschriftlicher Nachlaß [Reflexionen], Rel = Religion within the Boundaries of Mere Reason, Th-Danzig = Danzig Rational Theology According to Baumbach, Th-Pölitz = Lectures on the Philosophical Doctrine of Religion.

2 Although I will focus only on the conflict between Kant's MT and his theory of noumenal freedom, the former seems to conflict with some of Kant's other ideas about noumena, such as of noumena causally (and thus, necessarily) grounding phenomena (A288/B344); of God as an 'absolutely necessary being' both 
in the fourth antinomy (A452-3/B480-1) and in the 'Ideal of Pure Reason' (A584/B612); and of apperception as the 'original and necessary consciousness of the identity of oneself' (A108), which, according to for instance Pippin (1987), Kant takes to be the noumenal self.

3 One might suggest that Kant's remarks about the intuitive intellect in the CPJ (1790) simply cannot be rendered consistent with his theory of freedom and thus should be taken as pointing to a half-baked doctrine, the implications of which Kant had not fully grasped at the time of writing. However, first of all, as I noted above, a case can be made that Kant's conception of the intuitive intellect is not the only possible path to his MT that noumena lack modal properties, and that the MT is more integrated into Kant's theoretical philosophy than it appears to be. Second and more decisively, there is no clear evidence that Kant dropped his conception of the intuitive intellect after the CPJ or that this was a mere thought in flux around 1790. On the contrary, pretty much the same idea of the intuitive intellect and its specific features of representing objects appears as a well thought out and coherent doctrine in the CPR (1781/1787) (B138-9), and in his lectures spanning from the late 1770s to the mid-1790s (Met-L1, 28: 328-9 (1777-80); Th-Pölitz, 28: 1051-3 (1783-6?); Th-Danzig, 28: 1267 (1783-4); Met-K3, 29: 954-78 (1794-5)) as well as his handwritten notes from the late 1760s to the early 1780s (Refl 4017, 17: 387; Refl 4270, 17: 489; Refl 4297, 17: 499; Refl 5723, 18: 335). Thus, disregarding Kant's remarks at CPJ §76 is neither an attractive interpretative option, nor does it actually remove the textual problem at hand.

4 See Stang 2016: 198, n. 2, for his acknowledgement of Kohl for this construction.

5 See Baumgarten 1757: §§874-5; Eberhard 1781: \$69. Kant used both Baumgarten 1757 and Eberhard 1781 for his lectures exclusively devoted to rational theology in the 1780s, and thus the lecture notes transcribed by Kant's students cited here (Th-Danzig and Th-Pölitz) draw primarily on Kant's engagement with these two texts.

6 For a thorough discussion of this point, see Leech (2014).

7 See CPJ, 5: 407; Met-L1, 28: 328-9; Th-Danzig, 28: 1267; Refl 4270, 17: 489; Th-Pölitz, 28: 1051.

8 This is even clearer in the Danzig transcription: 'when possibility is considered in a thoroughgoing nexus with all other possible things, then one can say that what is possible in every nexus is also actual. In regard to God, therefore, since he knows everything possible in thoroughgoing nexus, there is no distinction between the possible and the actual' (Th-Danzig, 28: 1270). Winegar (2017) argues that divine cognition is amodal for exactly this reason.

9 See, for instance, A599/B627, B284, A230-2/B282-4; OPA, 2: 75. For a detailed account of Kant's rejection of the extensional understanding of modality, see my (2016) and (2019: ch. 7).

10 Stang 2016: 311. Stang's reasons for holding this view are unrelated to divine cognition and lie in his interpretation of Kant's claim that 'there are no non-existent objects' (p. 42).

11 Stang (2016: 314). Kant explicitly raises the question of the compatibility of human freedom with divine creation and, more specifically, the question of whether absolute spontaneity can be attributed to human soul, given that a human being, as created by God's free act, is ultimately a 'dependent being' (ens dependens) and an effect of another (Met-L1, 28: 257). For a detailed study of this very question, see Insole (2013).

12 One might here invoke Aristotle's account of potentiality, which appears to be more fundamental in his metaphysics than his account of modality. There are also contemporary metaphysical theories of potentiality such as the one defended by Vetter (2015) construing potentialities as dispositions of individual objects grounding metaphysical modalities rather than vice versa. However, not only is there no evidence that Kant would subscribe to such an essentialist metaphysic of potentiality or powers, but his understanding of modality as a feature of human discursivity would make such metaphysical deflation of modality unviable in the first place.

13 This is precisely what Chignell (2017) also complains about: 'Stang does not ... offer an analysis of noumenal power that does not itself invoke modal notions. Perhaps that is his point: we can only conceive of such powers in terms of what a substance or agent can do. But it remains unclear ... why the idea of a "non-modal noumenal power" is somehow legitimate and useful, rather than an empty, if inevitable, gesture that leads to explanatory circles.'

14 Kant is familiar with this reasoning from his predecessors. For instance, Baumgarten explicitly states that, although God's intuitive cognition does not rely on signs or symbols as human cognition does, God would still cognize signs, indirectly, by cognizing 'human souls'. See Baumgarten 1757: \$\$869, 871. See also Winegar (2017: 309-10) for a larger discussion of this point.

15 See A541/B569, A553/B582, A803/B831; G, 4: 446; CPrR, 5: 29, 97; Met-L1, 28: 257. 
16 See CPrR, 5: 95-6. While this is often taken to suggest an incompatibilist notion of freedom, notable compatibilist readings are available in the literature. See, for instance, Meerbote 1984; Hudson 1994. For the claim that neither category describes Kant's position, see Wood 1984.

17 See also A553/B581; Met-L1, 28: 267. It is important to note here that in the Groundwork, Kant offers a different positive notion of transcendental freedom as autonomy, the will's 'being a law to itself (4: 447). However, while this restricts freedom to moral actions and identifies free will with a good will or 'a will under moral laws' (4: 447), as I will discuss below, Kant's considered view actually allows free but heteronomous or evil actions.

18 For various expressions of this point, see Pereboom 2007: 542; Allison 2012: 105; Insole 2013: chs. 2, 3. 19 The worry of necessitarianism has been raised by Zammito 1992: 255-9 and Lord 2011: 98.

20 See OPA, 2: 77-83. Guyer (2006: 216) notes that Kant uses the same conceptual space for God's free creation of the world and human agents' free initiation of series of events.

21 On this point, see Pereboom 2007: 542; Allison 2012: 105; Hudson 1994: 4.

22 Stern (2004: 132) aptly formulates this as 'ought implies might not'. On the possibility of (free) violation of the moral law being a constitutive part of human moral agency, see also Kerstein 2002: 2 and Kohl 2015b: 699.

23 On this modal difference between the ways in which a law of nature and the moral law determine, see Watkins 2019: 14. Although Kant sometimes characterizes the moral law as the law of the causality of the noumenal will ( $G, 4: 446 ; \operatorname{CPrR}, 5: 105)$, this cannot mean that the moral law causes the will to comply with it, given his commitment to the absolute spontaneity of free rational will.

24 For the 'incorporation thesis', see Rel, 6: 23-4. Kant sometimes formulates noumenal freedom as complete independence from 'all influences of sensibility' (A541/B569) or 'all stimuli' (Met-L1, 28: 257). Obviously, only a holy will can have this kind of complete independence from the influences of sensibility. There are two interpretative options here. Either by 'independence' Kant means only independence from the causal determination of sensibility, or he refers to this kind of independence as a regulative ideal toward which we should strive. Allison (1990: 52) makes a case for the latter. Either way, however, sensuous affectability is a core feature of finite wills like ours.

25 On this point, see Wood 1984: 79-80; Allison 1990: 135 and 1998: 294-5.

26 See, for instance, Walker 1978: 148; Bennett 1984: 103; Vilhauer 2010: 54.

27 Hudson (1994: 26) points out that choosing, especially if it is pathologically affected, is a temporal process, and that Kant never offers a non-temporal account of choice.

28 See, for instance, Streumer 2007, for a defence of a negative reading of 'ought implies can' as 'can't cancels ought'.

29 Kant seems to hold that modality lies at the root of the other two discursive distinctions that we are constrained to make. He argues that we represent the moral law as an 'ought' and not as an 'is' because, in the case of our finite rationality, we can regard 'the action which is morally absolutely necessary ... physically as entirely contingent' (5: 403), and that we make the distinction between mechanism and teleology because we can only represent the particulars as contingent in relation to the universals or the whole $(5: 407)$. Both of these distinctions would be removed, if modality were to be removed from the representation of objects.

30 For various accounts of why OIC should be interpreted as a principle of blame or responsibility, see Blum 2000; Stern 2002: 47; Sinnott-Armstrong 1984: 250. It appears that the same modal representation that grounds blame should also ground praise in the case of moral success. However, for a recent argument that there is an asymmetry between the control conditions for praise and blame in Kant, and that Kant is committed to a weak requirement of alternate possibility only for moral blame, see Scholten 2021.

31 Some authors have defended a prescriptive reading of Kant's doctrine of radical evil, and in particular of his claim that every human is by nature evil, which when taken as a descriptive claim conflicts with Kant's commitments to human freedom, moral responsibility and moral progress. See, for instance, McMullin 2013 and Kohl 2017.

32 It might strike one as odd that I ought to attribute a property to a thing that I know to lack that property. However, this kind of 'as if epistemic attitude is not all that odd and unfamiliar to readers of Kant. For instance, as I noted above, Kant claims in the CPJ that we are subjectively constrained to represent natural organisms as if they are subject to teleological causation for heuristic reasons, even though we know that there is no trace of the distinction between teleological and mechanical causation 
in objective nature itself. Kant also holds that we must think of our minds as causally affected by things in themselves (A190, 387), even though we know that this representation is inadequate and due only to our finite, discursive cognitive make-up. Kohl (2015: 111), I think aptly, calls this a 'subjectively necessary fiction'. It is a core theme in the appendix to the CPR's Dialectic that reason is justified in employing ideas of the supersensible such as 'world-whole', 'God' and 'soul' in our empirical scientific investigations into nature as long as they are taken merely regulatively, that is, as offering mere goalposts for our investigations, and not as objective knowledge claims about the metaphysical constitutions of the world, God and soul. Similarly, I argue here, we are justified in assuming that human noumenal will can always have self-determined itself otherwise in our inquiries into moral responsibility and blame, even though we know that such modal attribution is not part of the objective description of human noumenal will. 33 It is important to see that (2) is, for a number of related reasons, not an item of practical cognition or what Kant calls a 'practical postulate'. First of all, while practical postulates 'ground' moral imperatives and thus are necessarily connected the moral law (JL, 9: 86; Log-D, 24: 751; Log-W, 24: 901; Refl 2798, 16: 518), (2) lacks such a necessary connection to the moral law or specific duties following from it but only regulates our judgements of blame based on the moral law. Second, while practical postulates, i.e. the assertions of freedom, God and immortality, have 'practical' objective validity thanks to that necessary connection to the moral law (CPrR, 5: 5), (2) has only prescriptive and subjective validity. Third, while through practical postulates what cannot be cognized but 'merely thought indeterminately and problematically' in the theoretical domain gets 'cognized assertorically' 'from a practical perspective' (CPrR, 5: 105, 134), (2), when taken descriptively as a metaphysical assertion, conflicts with what we can assert theoretically, i.e. the MT.

34 Stang (2016: 304-5) briefly considers something similar to this solution, but offhandedly dismisses without giving it a fair trial, claiming that such a solution would depend on the 'epistemic' interpretation of Kant's transcendental idealism, proposed, for instance, by Henry Allison, and that it 'is best equipped to resolve conflicts between the practical standpoint and the empirical-theoretical standpoint', whereas the antinomy he constructed 'represents a conflict between the practical standpoint and ... the "speculative-theological standpoint" ...' However, first, the idea that we can or even ought to adopt different 'standpoints' in considering ourselves or our actions is not dependent on a particular deflationary reading of Kant's idealism, but one that Kant himself employs ( $G, 4: 451 ; C P r R, 5: 98)$. Second, as I emphasized earlier, 'a speculative-theological' standpoint is not the only ground of Kant's 'noumenal amodalism' and thus the antinomy in question can be reconstructed as one precisely between 'practical' and 'empirical-theoretical' standpoints.

35 I would like to thank Iziah Topete, Ben Randolph, Brady Bowman, Colin Marshall and Reed Winegar for reading earlier versions of this article. I would also like to thank the two anonymous referees of Kantian Review for their very helpful comments.

\section{References}

Abaci, Uygar (2016) 'The Coextensiveness Thesis and Kant's Modal Agnosticism in the "Postulates"'. European Journal of Philosophy, 24(1), 129-58.

- (2019) Kant's Revolutionary Theory of Modality. Oxford: Oxford University Press.

Allison, Henry E. (1990) Kant's Theory of Freedom. Cambridge: Cambridge University Press.

- (1998) 'Morality and Freedom: Kant's Reciprocity Thesis'. In Paul Guyer (ed.), Kant's Groundwork of the Metaphysics of Morals: Critical Essays (Lanham, MD: Rowman \& Littlefield), 273-302.

- (2012) Essays on Kant. Oxford: Oxford University Press.

Baumgarten, A. G. (1757) Metaphysica. Halle: Hemmerde.

Beck, Lewis White (1987) 'Five Concepts of Freedom in Kant'. In Jan T. J. Srzednicki (ed.), Stephan Körner Philosophical Analysis and Reconstruction: Contributions to Philosophy (Dordrecht, Boston, Lancaster: Martinus Nijhoff Publishers), 35-51.

Bennett, Jonathan (1984) 'Kant's Theory of Freedom'. In Allen Wood (ed.), Self and Nature in Kant's Philosophy (Ithaca, NY, and London: Cornell University Press), 102-12.

Blum, Alex (2000) 'The Kantian versus Frankfurt'. Analysis, 60(3), 287-8.

Chignell, Andrew (2017) 'Review of Kant's Modal Metaphysics'. Notre Dame Philosophical Reviews (online, reviewed 6 September 2017). 
Eberhard, J. A. (1781) Vorbereitung zur natürlichen Theologie. Halle: Waisenhause.

Guyer, Paul (2006) Kant. New York: Routledge.

Hudson, Hud (1994) Kant's Compatibilism. Ithaca, NY, and London: Cornell University Press.

Insole, Christopher J. (2013) Kant and the Creation of Freedom: A Theological Problem. Oxford: Oxford University Press.

Kant, Immanuel (1900-) Gesammelte Schriften. Ed. Deutsche Akademie der Wissenschaften zu Berlin (and predecessors). Berlin: de Gruyter.

_ (1992-) The Cambridge Edition of the Works of Immanuel Kant. Ed. Paul Guyer and Allen W. Wood. Cambridge: Cambridge University Press.

— (2016) Danzig Rational Theology According to Baumbach. In Preparation for Natural Theology, ed. and trans. C. D. Fugate and J. Hymers. London: Bloomsbury.

Kerstein, Samuel J. (2002) Kant's Search for the Supreme Principle of Morality. New York: Cambridge University Press.

Kohl, Markus (2015a) 'Kant on the Inapplicability of the Categories to Things in Themselves'. British Journal for the History of Philosophy, 23(1), 90-114.

_ (2015b) 'Kant and “Ought Implies Can”'. Philosophical Quarterly, 65(261), 690-710.

_ (2017) 'Radical Evil as a Regulative Idea'. Journal of the History of Philosophy, 55(4), 641-73.

Leech, Jessica (2014) 'Making Modal Distinctions: Kant on the Possible, the Actual, and the Intuitive Understanding'. Kantian Review, 19(3), 339-65.

Lord, Beth (2011) Kant and Spinozism: Transcendental Idealism and Immanence from Jacobi to Deleuze. Houndmills: Palgrave.

McMullin, Irene (2013) 'Kant on Radical Evil and the Origin of Moral Responsibility'. Kantian Review, 18(1), 49-72.

Marshall, Colin (2018) 'Never Mind the Intuitive Intellect: Applying Kant's Categories to Noumena'. Kantian Review, 23(1), 24-40.

Meerbote Ralf (1984) 'Kant on the Nondeterminate Character of Human Actions'. In W. L. Harper and Ralf Meerbote (eds), Kant on Causality, Freedom, and Objectivity (Minneapolis: University of Minnesota Press), 138-63.

Pereboom, Derk (2007) ‘Kant on Transcendental Freedom'. Philosophy and Phenomenological Research, 73(3), 537-67.

Pippin, Robert (1987) 'Kant on the Spontaneity of Mind'. Canadian Journal of Philosophy, 17(2), 449-75.

Scholten, Matthé (2021) 'Ought Implies Can, Asymmetrical Freedom, and the Practical Irrelevance of Transcendental Freedom'. European Journal of Philosophy, 29(1), 25-42.

Sinnott-Armstrong, Walter (1984) “'Ought” Conversationally Implies “Can”'. Philosophical Review, 93(2), 249-61.

Stang, Nicholas F. (2016) Kant's Modal Metaphysics. Oxford: Oxford University Press.

Stern, Robert (2002) 'Does “Ought” Imply “Can”? And did Kant Think it Does?' Utilitas,16(1), 42-61.

Streumer, Bart (2007) 'Reasons and Impossibility'. Philosophical Studies, 136(3), 351-84.

Vetter, Barbara (2015) Potentiality: From Dispositions to Modality. Oxford: Oxford University Press.

Vilhauer, Benjamin (2010) 'The Scope of Responsibility in Kant's Theory of Free Will'. British Journal for the History of Philosophy, 18(1), 45-71.

Walker, Ralph (1978) Kant. Boston: Routledge.

Watkins, Eric (2019) Kant on Laws. Cambridge: Cambridge University Press.

Winegar, Reed (2017) 'Kant on God's Intuitive Understanding'. Kantian Review, 22(2), 305-29.

Wood, Allen (1984) 'Kant's Compatibilism'. In Allen Wood (ed.), Self and Nature in Kant's Philosophy (Ithaca, NY, and London: Cornell University Press), 73-101.

Zammito, John H. (1992) The Genesis of Kant's Critique of Judgment. Chicago: University of Chicago Press.

Cite this article: Abaci, U. (2022). Noumenal Freedom and Kant's Modal Antinomy. Kantian Review 27, 175-194. https://doi.org/10.1017/S1369415421000340 